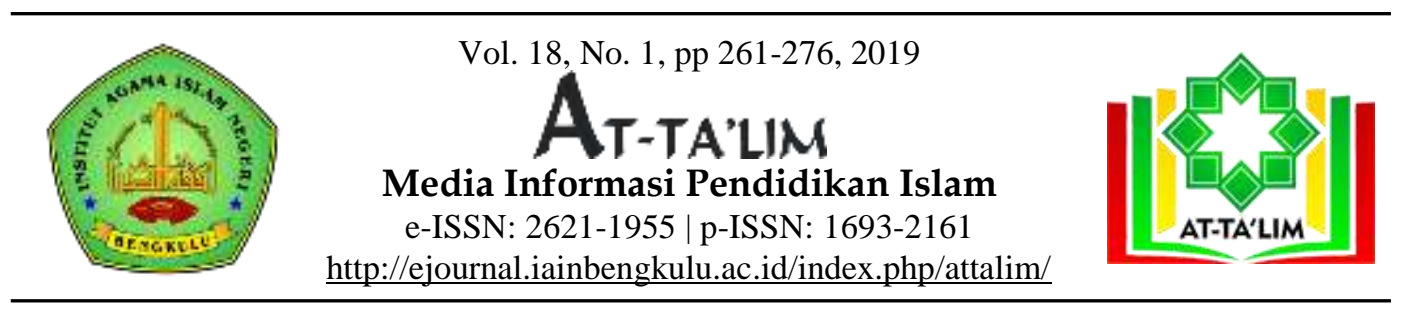

\title{
USAHA KEPALA SEKOLAH DALAM MENINGKATKAN Disiplin KERJA GURU (STUDI DESKRIPTIF KUALITATIF DI SMP N 1 ARGAMAKMUR KABUPATEN BENGKULU UTARA)
}

\author{
TISWARNI $^{1}$ \\ 1iswarnibahar63@gmail.com \\ 1SMP Negeri 1 Bengkulu Utara \\ Provinsi Bengkulu, Indonesia
}

\begin{abstract}
The Principal's Effort in Improving Teacher's Work Discipline (Qualitative Descriptive Study in SMP N 1 Argamakmur, North Bengkulu Regency). The purpose of this study was to describe the principal's efforts to improve teacher work discipline in Argamakmur 1 Junior High School, especially concerning: the presence of teachers in the classroom, making learning tools, implementing the teaching and learning process, preparing and using instructional media, carrying out assessments, and following up assessment results. The research method used in this study is qualitative descriptive. The subjects are principals, teachers and administrative staff. Data collection techniques used are interviews and observations. Data analysis techniques using inductive techniques Miles and Haberman models include: data collection, data reduction, data display and conclusion drawing / verification. The results of this study indicate that the principal's efforts to improve teacher work discipline in Argamakmur 1 Public Middle School have gone well.
\end{abstract}

Keywords: Principal Effort, Teacher's Work Discipline.

Abstrak: Usaha Kepala Sekolah dalam Meningkatkan Disiplin Kerja Guru (Studi Deskriptif Kualitatif di SMP N 1 Argamakmur Kabupaten Bengkulu utara). Tujuan penelitian ini adalah untuk mendeskripsikan usaha kepala sekolah dalam meningkatkan disiplin kerja guru di SMP Negeri 1 Argamakmur, terutama menyangkut: kehadiran guru di kelas, pembuatan perangkat pembelajaran, pelaksanaan proses belajar mengajar, menyiapkan dan menggunakan media pembelajaran, melaksanakan penilaian, serta menindaklanjuti hasil penilaian. Metode penelitian yang digunakan dalam penelitian ini adalah deskriptif kualitatif. Subjeknya adalah kepala sekolah, guru-guru dan staf administrasi. Tekhnik pengumpulan data yang digunakan adalah wawancara dan observasi. Tekhnik analisis data menggunakan teknik induktif model Miles dan Haberman yang meliputi: pengumpulan data, data reduction, data display dan conclusion drawing/verification. Hasil penelitian ini menunjukan bahwa usaha kepala sekolah dalam meningkatkan disiplin kerja guru di SMP Negeri 1 Argamakmur sudah berjalan dengan baik.

Kata Kunci: Usaha Kepala Sekolah, Disiplin Kerja Guru.

To cite this article:

Tiswarni (2019). Usaha Kepala Sekolah dalam Meningkatkan Disiplin Kerja Guru (Studi Deskriptif Kualitatif di SMP N 1 Argamakmur Kabupaten Bengkulu utara). At-Ta'lim: Media Informasi Pendidikan Islam, 18(1), 261-276. 


\section{A. INTRODUCTION / PENDAHULUAN}

Keberhasilan pendidikan di sekolah sangat ditentukan oleh keberhasilan kepala sekolah dalam mengelola tenaga kependikan yang tersedia di sekolah. Dalam hal ini, peningkatan produktifitas dan prestasi kerja dapat dilakukan dengan meningkatkan perilaku tenaga kependidikan di sekolah melalui aplikasi berbagai konsep manajemen personalia modern.

Kepala sekolah adalah pengelola pendidikan di sekolah secara keseluruhan, dan kepala adalah pemimpin pormal pendidikan di sekolahnya. Dalam suatu lingkunagan pendidikan di sekolah, kepala sekolah bertanggungjawab penuh untuk mengelola dan memberdayakan guru-guru agar terus meningkat kemampuan kirjanya.

Koordinasi yang baik di antara para anggota organisasi sekolah khususnya kepala sekolah sangat menentukan keberhasilan dalam mencapai tujuan. Keberhasilan sekolah dalam mewujudkan tujuan dapat dijadikan sebagai tolak ukur keberhasilan kepemimpinan kepala sekolah.

Berdasarkan studi pendahuluan yang dilakukan di SMP N 1 Argamakmur Kabupaten Bengkulu Utara diketahui bahwa sekolah ini merupakan sekolah paporit satu-satunya yang memiliki program akselarasi, serta sekolah ini dipersiapkan sebagai rintisan sekolah bersetandar internasional (RSBI). SMP N 1 Arga Makmur Kabupaten Bengkulu Utara merupakan sekolah pilihan utama di kota Arga Makmur bahkan di Kabupaten Bengkulu Utara, kepercayaan masyarakat sangat tinggi terhadap program-program yang ada, dibuktikan dengan banyaknya prestasi yang didapat para siswa baik ditingkat Kabupaten, provinsi, maupun ditingkat Nasional. Disamping itu sekolah ini juga merupakan pusat pelaksanaan musyawarah guru mata pelajaran ( MGMP). Walaupun demikian, di SMP N 1 Arga Makmur masih ditemukan guru-guru yang tidak disiplin masuk kelas, 
dalam pembuatan perangkat pembelajaran. Pemakaian alat media pembelajaran, melaksanakan penilaian serta menindaklanjuti hasil penilaian tersebut.

Karna itu tingkat kedisiplinan sangat dibutukan dan dituntut usaha para sekolah untuk menumbukan kedisiplinan tersebut. Untuk mengetahui lebih jauh tentang usaha kepala sekolah SMP N 1 Arga Makmur Kabupaten Bengkulu Utara dalam meningkatkan disiplin guru maka perlu diadakan penelitian yang komprehensif. Penelitian ini menyangkut berbagai usaha kepala sekolah dalam rangka meningkatkan disiplin kerja guru di SMP N 1 Arga Makmur Kabupaten Bengkulu Utara. Berdasarkan uraian di atas, penulis merasa perlu untuk mengadakan suatu penelitian tentang usaha kepala sekolah dalam meningkatkan disiplin kerja guru di SMP N 1 Arga Makmur.

\section{B. TuJuAn PENELITIAN}

Secara umum, tujuan penelitian ini yaitu: untuk mendiskripsikan usaha kepala sekolah meningkatkan kerja guru di SMP N 1 Arga Makmur Kabupaten Bengkulu Utara.

Secara khusus,yaitu:

1. Mendiskripsikan bagaimana usaha kepala sekolah meningkatkan disiplin kerja guru dalam kehadiran di klas.

2. Mendiskripsikan bagaimana usaha kepala sekolah meningkatkan disiplin kerja guru dalam melaksanakan pembuatan perangkat pembelajaran

3. Mendiskripsikanbagaimanausahakepalasekolahmeningkatkandisip linkerjaguru dalam melaksanakan proses pembelajaran

4. Mendiskripsikanbagaimanausahakepalasekolahmeningkatkandisip linkerjaguru dalam menyiapkan dan menggunakan media pembelajaran

5. Mendiskripsikanbagaimanausahakepalasekolahmeningkatkandisip linkerjaguru dalam melaksanakan penilaian 
6. Mendiskripsikanbagaimanausahakepalasekolahmeningkatkandisip linkerjaguru dalam menindak lanjuti hasil penilaian.

\section{KAJIAN PUSTAKA}

\section{a. Diskripsi Teoritis}

\section{a) Disiplin Kerja Guru}

Manusia dalam suatu organisasi dipadang sebagai sumber daya manusia tentulah harus memiliki kualitas dan disiplin dalam melaksanakan kegiatan atau pekerjaannya. Seorang guru harus memiliki disiplin yang tinggi dalam melaksnakan pekerjaannyayaitu mengajar, dengan disiplin tinggi disharapkan memiliki dampak yang positif terhadap siswa dalam menerima pelajaran dari guru yang mengajar dan sesama rekan guru lainnya. Ada beberapa faktor menentukan kualitas tenaga kerja yaitu tingkat kecerdasan, bakat, sifat kepribadian, tingkat pendidikan kualitas fisik, etos (semagat kerja) dan disiplin kerja. Kualitas sumber daya seperti inilah yang dimiliki oleh negara-negara yang telah maju.

Disiplin adalah suatu keadaan dimana orang-orang yang tergabung dalam suatu organisasi tunduk pada peraturan-peraturan yang telah ada dengan rasa senang hati. Disiplin mengalami perkembangan makna dalam beberapa pengertian. Pertama, disiplin diartikan sebagai kepatuhan terhadap peraturan atau tunduk pada pengawasan dan pengendaliaan. Kedua, disiplin sebagai latihan yang bertujuan mengembangkan diri agar dapat berprilaku tertib. Disiplin adalah ketaatan pada peraturan (tata tertib) (Depdiknas, 2009).

Menurut Siagian disiplin kerja merupakan tindakan manajemen untuk mendorong para staf agar memenuhi berbagai kebutuhan yang harus di laksanakan. Sikulah mengatakan bahwa disiplin berarti mentaati dan menghargai setiap perjanjian yang dibuat antara perusahaan dan karyawan. "discipline is manajement as action to and force organization standarts" yang berarti bahwa pimpinan kerja adalah 
pelaksana manajemen untuk mempertegu pedoman-pedoman organisasi (Mangkunegara, 2006).

Dari pendapat di atas dapat diambil makna disiplin merupakan aturan atau tindakan atau prosedur yang diterapkan dan dihargai yang dibuat suatu organisasi untuk mengontrol atau mengawasi anggota organisasinya.

Disiplin kerja yang tinggi tidak muncul begitu saja tetapi merupakan suatu proses belajar yang terus menerus. Proses pembelajaran agar dapat efektif maka pemimpin yang merupakan agen pengubah perlu memperhatikan prinsip-prinsip konsisten, adil bersikap, dan terbuka.

Guru adalah semua orang yang wewenang dan bertnaggung jawab terhadap pendidikan murid, baik secara individual maupun klasikal, baik disekolah maupun di luar sekolah (Djamarah \& Zain, 2002). Guru adalah subjek utama dalam pelaksanaan proses pendidikan dan pembelajaran yang menjadi inti kegiatan pendidikan. Guru berfungsi mengoptimalkan potensi anak didik (Danim, 2002).

Guru merupakan jabatan propesional, secara etimologi propesi berasal dari bahasa inggris yaitu profession atau bahasa latin yaitu profecus, yang artinya mengakui, pengakuan, menyatakan mampu atau ahli dalam melakukan pekerjaan. Secara terminologi profesi dapat diartikan sebagai pekerjaan yang mempersyaratkan pendidikan tinggi bagi pelakunya yang ditekankan pada pekerjaan mental. Ada tiga pilar pokok yang ditunjuk untuk suatu profesi, yaitu: (1). Pengetahuan, kapasitas kofnitif yang dimiliki soseorang melalui proses belajar, (2). Keahlian, penguasaaan yang dapat dijadikan acuan derajat profesional diperlukan persyaratkan khusus ( Danim \& Suparno, 2008).

Sedangkan guru sebagai pengajar adalah membantu peserta didik yang sedang berkembang untuk mempelajari sesuatu yang belum diketahuinya, membentuk konpentensi, dan memahami materi standar yang lain di pelajari. 
Mengajar berarti meneruskan dan mengembangkan ilmupengetahuan dan teknologi (Rusman \& Rahmah, 2010). Guru harus menguasai materi yang akan di ajar, menguasai penggunaan strategi dan metode mengajar yang akan digunakan untuk menympaikan bahan ajar, dan menentukan alat evaluasi pendidiikan yang akan digunakan untuk menilai hasil belajar siswa, aspej-aspek manajemen kelas dan dasar-dasar kependidikan (Suparlan, 2006).

Guru memiliki tugas yang beragam dan berimplementasi dalam bentuk pengabdian, tugas tersebut meliputi bidang profesi, bidang kemanusian, dan bidang kemasyarakatan.

Proctor dan traton dalam hasibuan mengatakan bahwa pembinaan disiplin tenaga kerja berfungsi untuk menaikan rasa kepuasan pegawai, mengurangi ketidakhadiran, absensi dan perputaran pegawai, memperbaiki metode dan sistem kerja, menaikan tingkat penghasilan, mengurangi biaya lembur, mengurangi biaya pemeliharaan mesin, memperbaiki komunikasi, moral pegawai, meningkatkan pengetahuan sebagai pegawai, menimbulkan kerjasam yang lebih baik.

Berdasarkan uraian diatas, maka pengertian disiplin guru yang dimaksud dalam penelitian ini adalah sikap atau tingkah laku seorang guru yang mencerminkan tingkat kepatuhan atau ketaatanya kepada berbagai ketentuan yang berlaku, dan tindakan korektif terhadap pelanggaran atas ketentuan atau standar yang telah ditetapkan.

\section{b) Usaha Kepala Sekolah Dalam Meningkatkan Disiplin Kerja} Guru

Kepala sekolah dapat diartikan sebagai pemimpin sekolah atau suatu lembaga dimana tempat menerima dan memberi pelajaran. Menurut Wahjosumidjo kepala sekolah adalah srorang tenaga fungsional guru yang diberi tugas tambahan untukmemimpin suatu sekolah dimana diselenggarakannya proses belajar mengajar, atau 
tempat dimana terjadi interaksi antara guru yang memberi pelajaran dan murid yang menerima pelajaran.

Kepala sekolah yang ingin berhasil menggerakan para guru/staf dan para siswa agar berprilaku dalam mencapai tujuan sekolah adalah 1) menghindari diri dari sikap dan perbuatan memaksa atau bertindak keras terhadap guru, staf, dan siswa. 2) harus mampu melakukan perbuatan yang melahirkan kemauan untuk bekerja dengan penuh semangat dan percaya diri terhadap para guru, staf dan siswa (Atmosudirjo, 2000).

Sebagai manajer pendidikan kepala sekolah harus berusaha untuk memperbaiki proses belajar mengajar dengan cara tidak bosanbosannya membimbing guru agar menjadi guru yang profesional, atau selalu melakukan monev, dan lebih sering melakukan supervisi.

Supervisi adalah bantuan dalam mengembangkan situasi belajar mengajar agar memperoleh kondisi yang lebih baik. Meskipun tujuan akhirnya tertuju pada hasil belajar siswa, namun yang diutamakan dalam supervisi adalah membantu guru, yang pada akhirnya berdampak pada keadaaan siswa (Arikunto, 2002).

Dari uraian diatas dapat disimpulkan bahwa kepala sekolah sebagai pengelola hendaknya berdasarkan pada standar pengelolaan yaitu standar nasional pendidikan dengan perencanaan, pelaksanaan, dan pengawasan kegiatan pendidikan pada tingkat satuan pendidikan agar tercapai efisiensi dan efektivitas penyelenggaraan pendidikan.

Pembinaan disiplin kerja guru adalah usaha kepala sekolah untuk memperbaiki efektifitas kerja guru dalam mencapai hasil-hasil kerja yang telah ditetapkan dengan maksud untuk memperbaiki penguasaan keterampilan dan teknik-teknik pelaksanaan pekerjaan tertentu (handoko).

Berdasarkan semua uraian diatas nampak bahwa, usaha kepala sekolah dalam meningkatkan disiplin guru memiliki banyak indikator kefisiplinan guru yang dapan diukur, namun dalam penelitian ini 
akan dibatasi beberapa hal saja. Disiplin guru diukur sebagai gambaran loyalitas bawahan, yang dilandasi adanya kesadaran dan tanggung jawab terhadap tugas secara rasional, cermat, dan tertib.

\section{c) Hasil Penelitian Yang Relevan}

Purnama sari dalam tesisnya "usaha kepala sekolah dalam meningkatkan disiplin guru (studi deskriftif kualitatif di SMP N Muara Beliti Kabupaten Musi Rawas) menyimpulkan bahwa kepalah SMP N Muara Beliti Kabupatrn Musi Rawas telah melaksanakan usahanya dengan cukup baik selaku kepala sekolah dalam meningkatkan disiplin guru.

Kemudian Nirwan Sukardi dalam tesisnya "Hubungan antara penilaian guru terhadap kepemimpinan kepala sekolah dan disiplin kerja guru SMA N Kota Bengkulu" menyimpulkan bahwa 1) terdapat hubungan positif antara kepemimpinan kepala sekolah dengan disiplin kerja guru. 2) terdapat hubungan yang positif antara kepemimpinan kepala sekolah dengan kepuasan kerja guru.

Warsito dalam tesisnya" peran kepala sekolah sebagai administrator dan supervisor dalam meningkatkan kinerja guru di SD plus al firdaus surakarta" menunjukan bahwa 1) peranan kepala sekolah sebagai administrator dan supervisor disekolah telah diterapkan secara maksimal dan diterima oleh guru. 2) meningkatnya kinerja gurudiSDplusalfirdaussurakarta ternyata banyak dipengaruhi oleh peran kepala sekolah. 3) asumsi bahwa administrasi menjadi beban bagi guru serta supervisi menjadi momok bagi guru dapat dikurangi melalui pendekatan dan motivasi oleh peran kepala sekolah.

Dari ketiga laporan diatas antara lain menunjukan bahwa ada hubungan yang sangat tinggi antarafaktor-faktor yang berhubungan dengan kepala sekolah sebagai pemimpin, administrator, dan supervisor terhadap disiplin kerja dan kepuasan kerja guru. 


\section{d) Paradigma Penelitian}

Penelitian yang dilakukan ini berangkat dari paradigma berpikir sistematik yang dapat digambarkan sebagai berikut:

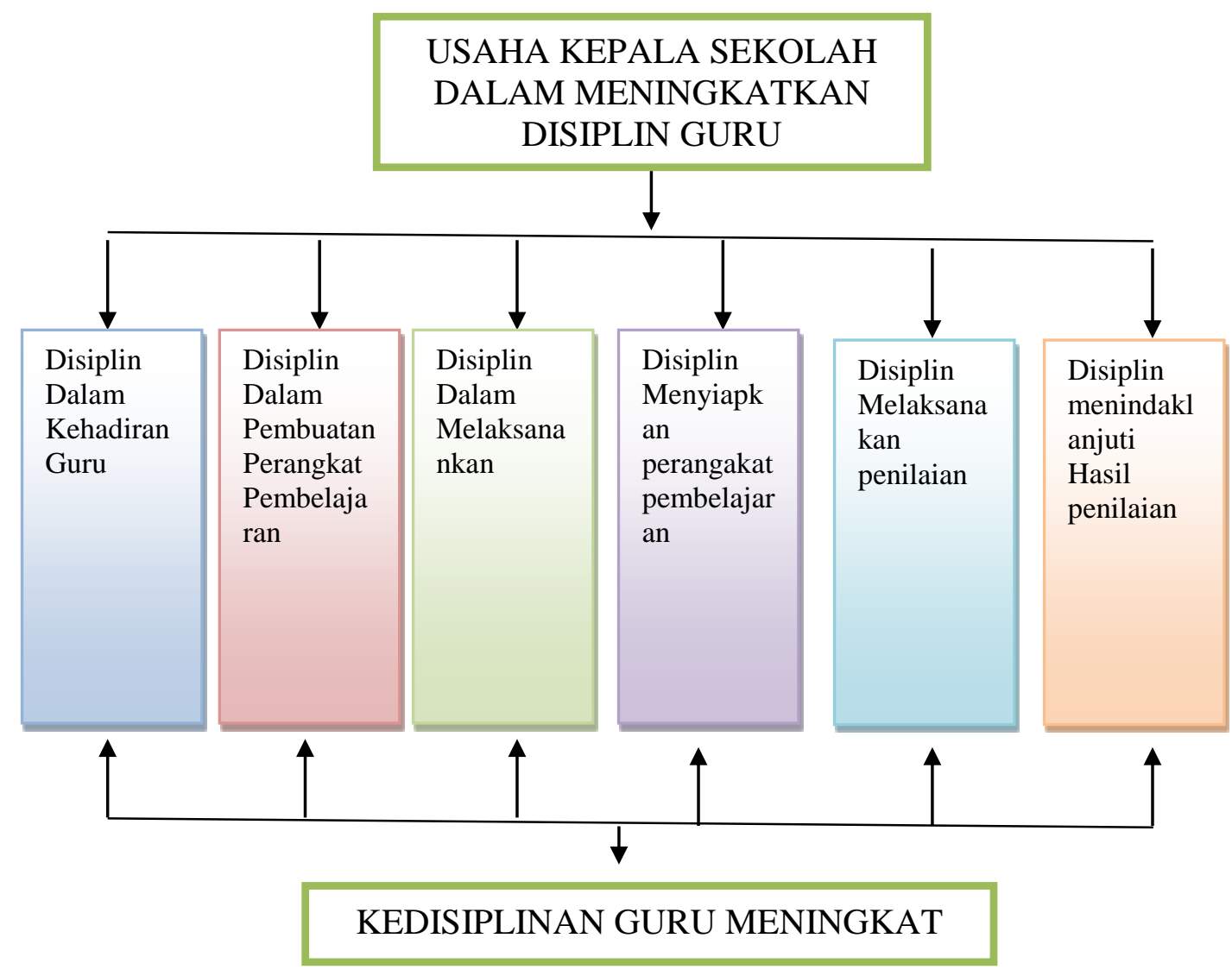

D. Metode PENELITIAN

Metodelogi penelitian ini adalah penelitian deskriptif kualitatif, penggunaan penelitian kualitatif dalam pendidikan bertujuan untuk mendeskripsikan suatu proses kegiatan pendidikan berdasarkan apa yang terjadi dilapangan sebagai bahan kajian lebih lanjut untuk menemu kenali kekurangan dan kelebihan pendidikan sehingga dapat ditentukan upaya penyempurnaannya (Zuriah, 2002).

Subjek penelitian dalam penelitian ini adalah kepala sekolah dan guru-guru di SMP N 1 Argamakmur Kabupaten Bengkulu Utara. Teknik pengumpulan data yang digunakan oleh peneliti adalah pendekatan, observasi, wawancara dan dokumentasi. Instrumen 
penelitian ini adalah peneliti itu sendiri, peneliti langsung menggali data yang diperlukan untuk menjaga orisinilitas data. Teknik analisis data yang digunakan adalah analisis kualitatif deskriptif yang terdiri dari pengumpulan data, reduksi data, penyajian data, dan penarikan kesimpulan dan verifikasi.

\section{E. HASIL PENELITIAN}

Penelitian ini memfokuskan hal-hal yang berhubungan dengan usaha kepala sekolah dalam meningkatkan disiplin guru di SMP Negeri 1 Argamakmur.

Fokus penelitian ini adalah sebagai berikut:

\section{a. Usaha kepala sekolah meningkatakan disiplin kerja guru dalam} kehadiran dalam kelas di SMP Negeri 1 Argamakmur

Kehadiran merupakan usaha pertama yang dilakukan dalam rangka pendisiplinan seseorang. Dengan kehadiran seseorang di sekolah khususnya di dalam kelas tentu akan menjadi awal terlaksananya proses belajar mengajar disekolah. Kepala sekolah sebagai seorang pemimpin disekolah tentu bertanggung jawab penuh terhadap penegakan disiplin guru yang ada disekolah yang dipimpinnya. Kepala sekolah melakukan usaha meningkatkan disiplin kerja guru khususnya dalam kehadiran mengajar di kelas.

Usaha yang yang dilakukan oleh kepala sekolah dalam meningkatkan disiplin kerja guru dalam hal kehadiran mengajar dalam kelas yaitu; membuat absen kehadiran yang harus diisi oleh guru tiap hari, menyiapkan absen dalam kelas, menunjuk petugas khusus yang merekap absen setiap hari, masing-masing ada yang bertugas merekap absen kelas VII, kelas VIII, dan kelas IX, memberi teguran kepada guru yang sering terlambat masuk kelas, melakukan pembinaan pada saat rapat koordinasi bulanan, memberikan penghargaan kepada guru yang memiliki disiplin yang tinggi 
kehadiran mengajar dalam bentuk pengusulan guru berprestasi, DP3, walaupun penghargaan yang berupa materi belum ada.

b. Usaha kepala sekolah meningkatakan disiplin kerja guru dalam membuat perangkat pembelajaran di SMP Negeri 1 Argamakmur

Membuat perangkat pembelajaran merupakan tugas seorang guru untuk membuat dan melengkapinya yang merupakan keharusan dilakukan seorang guru sebelum mereka memberikan materi pembelajaran. Perangkat pembelajaran tersebut terdiri dari: silabus program tahunan, yang dibuat setiap awal semester. Sedangkan rencana pelaksanaan pembelajaran harus disiapkan sebelum guru mengajar.

Usaha yang yang dilakukan oleh kepala sekolah dalam membuat perangkat pembelajaran di SMP Negeri 1 Argamakmur yaitu: mengadakan rapat koordinasi pembagian tugas; mengadakan MGMP, mengadakan pendampingan oleh guru senior mata pelajaran sejenis, membuat jadwal batas akhir penyerahan perangkat pembelajaran, membuat buku control perangkat pembelajaran, dan melaksanakan rapat pembinaan.

c. Usaha kepala sekolah meningkatakan disiplin kerja guru dalam melaksanakan pembelajaran

Kedisiplinan guru dalam hal melaksanakan pembelajran merupakan hal yang pentinguntuk diperhatikan. Dalam pelaksanaan pembelajaran dibutukan guru yang berkompeten dalam segala hal, agar materi pelajaran dapat dengan maksimal diserap oleh anak didik. Kekonsistenan terhadap waktu dan jadwal dlam melaksanakan pengajaran diharapkan agar guru tersebut tidak menggangu jadwal atau waktu pelajaran yang lainnya sehingga pelaksanaan pembelajran dapat berlangsung dengan tertib.

Usaha yang yang dilakukan oleh kepala sekolah dalam melaksanakan pembelajaran di SMP Negeri 1 Argamakmur yaitu; adanya daftar hadir dikelas yang dilengkapi dengan jurnal kelas 
masing-masing, melaksanakan supervisi kelas, rapat pembinaan, memberikan teguran dan memberikan teguran kepada guru yang tidak disiplin.

d. Usaha kepala sekolah meningkatakan disiplin kerja guru dalam menyiapkan dan menggunakan media pembelajaran

Dalam menyiapkan dan menggunakan media pembelajaran, kepala SMP Negeri 1 argamakmur berusaha untuk dapat menyediakan media pembelajaran untuk memaksimalkan proses pembelajaran.

Usaha yang yang dilakukan oleh kepala sekolah dalam menyiapkan dan menggunakan media pembelajaran di SMP Negeri 1 Argamakmur yaitu; membuat anggaran khusus untuk pengadaan media pembelajaran memotivasi guru untuk menyiapkan media pembelajaran pada saat rapat pembinaan.

\section{e. Usaha kepala sekolah meningkatakan disiplin kerja guru dalam melaksanakan penilaian}

Penilaian pembelajaran merupakan kegiatan pembelajaran untuk mengetahui sejauh mana tingkat kemampuan siswa memahami materi yang disampaikan oleh guru. Memberi penilaian atau mengevaluasi merupakan hal yang harus dilakukan seorang guru pada kegiatan belajar mengajar.

Usaha yang yang dilakukan oleh kepala sekolah dalam melaksanakan penilaian di SMP Negeri 1 Argamakmur yaitu; menyiapkan daftar nilai, mengumpulkan nilai ke wakil kepala sekolah dan wali kelas, kepala sekolah mengingatkan dalam rapat, memberikan teguran bagi guru yang tidak mengumpulkan daftar nilai.

\section{f. Usaha kepala sekolah meningkatakan disiplin kerja guru dalam menindaklanjuti hasil penilaian}

Meningkatkan disiplin guru dalam hal menindaklanjuti hasil penilaian adalah merupakan kegiatan yang harus dilakukan guru setelah melaksanakan penilaian. Dari hasil penilaian inilah dapat ditentukan apa yang akan dilakuakn sebagai tindak lanjut dari peorolehan seorang siswa. Tentunya setelah melaksanakan langkah- 
langkah penilaian diantaranya melaksanakan ulangan, mengoreksi hasil ulangan, menganlisis hasil ulangan dan menindaklanjuti hasil ulangan tersebut.

Usaha yang yang dilakukan oleh kepala sekolah dalam menindaklanjuti hasil penilaian di SMP Negeri 1 Argamakmur yaitu; menekankan dalam rapat koordinasi, menyiapkan blanko untuk program perbaikan dan pengayaan, memberikan teguran bagi guru yang tidak melaksanakan program perbaikan dan pengayaan.

\section{F. KESIMPULAN}

Berdasarkan latar belakang masalah, permasalahan, rumusan masalah dan hasil penelitian serta pembahasan dapat disimpulkan bahwa kepala sekolah SMP N 1 Argamakmur telah melakukan usahanya selaku kepala sekolah dalam meningkatkan disiplin kerja guru.

\section{G.REFERENCES / DAFTAR PUSTAKA}

Agustriana, N. (2019). Pengaruh Metode Edutainment Dan Identitas Diri Terhadap Keterampilan Sosial Anak. Al-Fitrah, 1(2), 216-228. Retrieved from http://ejournal.iainbengkulu.ac.id/index.php/ alfitrah/article/ view/1517

Arikunto, Suharsimi. (2002). Prosedur Penelitian: Suatu Pendekatan Praktek., Prajudi. 1976. Jakarta: Rineka Cipta

Avin Fadilah Helmi. Disiplin Kerja. Http://Avin.Staff.Ugm.Ac.Id./ Data/Jurnal. (Diunduh 1 Oktober 2011)

Colvin. Geoff. (2008). 7 Langkah Untuk Menyusun Rencana Disiplin Kelas Proaktif. Pt.Mancanan Jaya Cemerlang.

Danim. Sudarwan. (2002). Inovasi Pendidikan Dalam Upaya Peningkatan Profgesionalisme Tenaga Kependidikan. Bandung:Cv Pustaka Setia.

Danim. Sudarwan. Dan Suparno. (2008). Manajemen Dan Kepemimpinan Transpormasional Kekepalasekolahan: Visi Dan Strategi Sukses Era 
Teknologi, Situasi Krisisdan Internasionalisasi Pendidikan. Jakarta: Rineka Cipta.

Depdikbud. (1996). Petunjuk Peningkatan Mutu Pendidikan Disekolah Dasar. Jakarta:Depdikbud

Depdikbud. (1999). Panduan Manajemen Sekolah. Jakarta : Direktorat Jendral Pendidikan Dasar Dan Menengah

Depdikbud. (2003). Undang-Undang Sistem Pendidikan Nasional. Surabaya: Karina.

Depdiknas. (2009). Pedoman Pelaksanaan Tugas Guru Dan Pengawas Pmptk. Jakarta Direktur Jendral.

Djamarah. S.B, \& Zain. A. (2002). Strategi Belajar Mengajar. Jakarta : Rineka Cipta.

Freire. P. (1999). Politik Pendidikan. (Terjemahan Agung Prihantoro E Fuad Arif Fudiyartono). Yogyakarta: Pustaka Pelajar Dan Read.

Gambiro, Bambang. (2005). Pengaruh Kualitas Kepemimpinan Kepala Sekolah Dalam Persepsi Guru, Motivasi Berprestasi, Dan Kompetensi Terhadap Kedisiplinan Guru Sekolah Dasar. Yogyakarta: Tesis Mmp Uny.

Gibson. J.W. (1996). Organisasi Dan Manajemen, Perilaku Struktur Dan Proses. ( Terjemahan Agung Prihantoro). Jakarta: Bumi Aksara.

Kurniah, N., Andreswari, D., \& Kusumah, R. G. T. (2019). Achievement of Development on Early Childhood Based on National Education Standard. In Proceedings of the International Conference on Educational Sciences and Teacher Profession (ICETeP 2018) (pp. 351-354). Paris, France: Atlantis Press. https://doi.org/10.2991/icetep-18.2019.82

Kusumah, R. G. T. (2019). Peningkatan Kemampuan Berfikir Kritis Mahasiswa Tadris IPA Melalui Pendekatan Saintifik Pada Mata kuliah IPA Terpadu. IJIS Edu: Indonesian Journal of Integrated Science Education, 1(1), 71-84. Retrieved from http://ejournal.iainbengkulu.ac.id/index.php/ijisedu/article/view $\angle 1762$

Kusumah, R. G. T., \& Munandar, A. (2017). Analysis Of The Relationship Between Self Efficacy And Healthy Living Conciousness Toward Science Learning Outcome. EDUSAINS, 9(2), 132-138. https://doi.org/10.15408/ES.V9I2.2183 
Kompensasi Kerja. Bpk Penabur. Http://Www.Bpkpenabur.Or.Id/Files (Diunduh Sabtu 1 Oktober 2011)

Liang, The Gie. (2001). Cara Belajar Yang Efisien. Yogyakarta: Pusat Kemajuan Studi.

Mangkunegara, A.A Anwar Prabu. (2006). Perencanaan Dan Pengembangan Sumber Daya Manusia. Cetakan Ke-2. Bandung: Refika Aditama.

Moleong, I.J. (2002). Metode Penelitian Kualitatif. Bandung: Remaja Rosdakarya.

Miles, Bm \& Hubermen, Am. (1992). Analisis Data Kualitatif. Jakarta. Ui Press.

Mulyasa. (2009). Menjadi Kepala Sekolah Profesional. Bandung: Pt. Remaja Rosdakarya.

Mulyasa. (2009). Manajemen Berbasis Sekolah (Konsep, Strategi Dan Implementasi). Bandung: Pt. Remaja Rosdakarya.

Nitisemito, Alex. (1982). Manajemen Personalia. Jakarta: Ghalia Indonesia.

Peraturan Menteri Pendidikan Nasional Republik Indonesia Nomor 22 Tahun 2006. Tentang Standar Isi Untuk Satuan Pendidikan Dasar Dan Menengah, Jakarta: Depdiknas

Peraturan Menteri Pendidikan Nasional Republik Indonesia Nomor 23 Tahun 2006. Tentang Standar Kompetensi Lulusan Untuk Satuan Pendidikan Dasar Dan Menengah, Jakarta: Depdiknas

Peraturan Menteri Pendidikan Nasional Republik Indonesia Nomor 19 Tahun 2005. Tentang Standar Nasional Pendidikan , Jakarta: Depdiknas

Robbins, Sp. (1992). Essentoels Of Organizational Behavior. New York: Prentice Hall International, Inc.

Rusman, H.T. \& Rahman, Abd. (2010). Panduan Pengembangan Profesi Guru Dan Ptk. Depok : Karima.

Sagala Syaiful. (2007). Managemen Stategik Dalam Peningkatan Mutu Pendidikan. Bandung. Alfabeta.

Sapri, J., Agustriana, N., \& Kusumah, R. G. T. (2019). The Application of Dick and Carey Learning Design toward Student's Independence and Learning Outcome. In Proceedings of the International Conference on Educational Sciences and Teacher Profession (ICETeP 2018) (pp. 218222). Paris, France: Atlantis Press. https://doi.org/10.2991/icetep- 
18.2019 .53

Sedarmayanti, Hidayat, Syarifudin. (2002). Metodologi Penelitian. Bandung: Mandar Maju.

Suparlan. (2006). Guru Sebagai Profesi. Yogyakarta: Hidayat.

Sugiyono. (2006). Metode Penelitian Kualitatif, Kualitatif Dan RED. Bandung : Alfabeta.

Staf Dosen Balai Pembinaan Administrasi Ugm. (1982). Ensiklopedi Administrasi Pt. Gunung Agung Jakarta

Sasongko, Rambat Nur Dkk. (2011). Pedoman Penulisan Karya Ilmiah, Bengkulu: Prodi Mamp Pps Fkip Universitas Bengkulu.

Tesis Sunardi. Http://Guru Falah.20 M.Com/ Tesis Sunardi (Sabtu 1 Oktober 2011)

Unaradjan. Dolet. (2003). Manajemen Disiplin. Jakarta: Grasindo.

Undang-Undang Ri No. 20 Tahun 2003, Tentang Sistem Pendidikan Nasional

Undang-Undang Ri No. 14 Tahun 2005 Tentang Guru Dan Dosen

Universitas Bengkulu. (2011). Pedoman Penulisan Karya Ilmiah (Penulisan Makalah, Laporan Referensi, Dan Tes Pendidikanis). Bengkulu: Program Studi Magister Manajemen.

Yunus, A. (2010). Usaha Kepala Sekolah Dalam Membina Disiplin Mengajar Guru. Jurnal Ilmiah Manajemen Pendidikan Program Pascasarjana Fkip Universitas Bengkulu. 3 Maret 2011 9-14

Yunus, A. (2010). Usaha Kepala Sekolah Dalam Membina Disiplin Mengajar Guru. Jurnal Ilmiah Manajemen Pendidikan Program Pascasarjana Fkip Universitas Bengkulu. 1 Maret 2011 39-52 